\title{
Anticholinergic Burden and Associated Healthcare Resource Utilization in Older Adults with Overactive Bladder
}

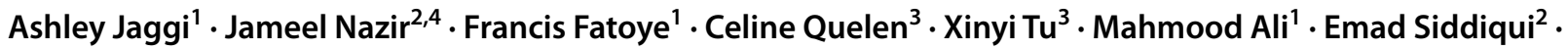 \\ Patrick J. O. Covernton ${ }^{2} \cdot$ Margarita Landeira ${ }^{2} \cdot$ Nurul Choudhury $^{2,5}$
}

Accepted: 20 June 2021 / Published online: 13 August 2021

(c) The Author(s) 2021

\begin{abstract}
Background Bladder anticholinergics are the most widely used drugs to treat overactive bladder $(\mathrm{OAB})$ but can contribute to cumulative anticholinergic burden, which may be associated with adverse outcomes.

Objective This study aimed to evaluate the association between cumulative anticholinergic burden and healthcare resource utilization (HRU) and costs in older adults with OAB.

Materials and Methods This was a retrospective, observational study that used data from the UK Clinical Practice Research Datalink (CPRD) GOLD database. Participants were aged $\geq 65$ years with $\geq 3$ years of continuous enrolment before and $\geq 2$ years after the index date (date of OAB diagnosis or first prescription for any OAB drug between 1 April 2007 and 31 December 2015). The primary endpoint was the association between cumulative anticholinergic burden (assessed using the Anticholinergic Cognitive Burden [ACB] scale during the 3-year pre-index period) and HRU (GP consultations, specialist referrals, urological tests, hospital admissions) over the 2-year post-index period.

Results Data from 23,561 adults were included in the analysis. Mean (SD) ACB scores in the pre- and post-index periods were 1.0 (1.1) and 2.4 (1.7), respectively; urological drugs contributed most (58.8\%) to the latter. For the primary endpoint, higher pre-index ACB scores were associated with higher post-index HRU and costs. Mean (SD) ACB scores in the post-index period were 1.2 (1.3) and 2.5 (1.7) in those treated with mirabegron (beta-3 agonist) or bladder anticholinergics, respectively. Limitations The generalizability of the results outside the UK is unclear.

Conclusions In older adults with OAB, higher anticholinergic burden before initiating OAB drugs is associated with higher HRU and costs. When making treatment decisions in older adults, consideration should be given to assessing the existing anticholinergic burden and using $\mathrm{OAB}$ treatments that do not add to this burden.
\end{abstract}

\section{Introduction}

Pharmacological options for overactive bladder (OAB) include bladder anticholinergic agents and beta-3 agonists (e.g., mirabegron) [1-4]. Bladder anticholinergic agents are the most widely used OAB drugs; they are effective,

Ashley Jaggi

ashleyjaggi@hotmail.com

1 Manchester Metropolitan University, Manchester M15 6GX, UK

2 Astellas Pharma Europe Ltd, Addlestone, UK

3 Creativ-Ceutical, London, UK

4 Present Address: Swedish Orphan Biovitrum AB, Stockholm, Sweden

5 Present Address: AstraZeneca, Södertälje, Sweden

\section{Key points}

Older people ( $\geq 65$ years) with overactive bladder $(\mathrm{OAB})$ are likely to have some underlying anticholinergic burden due to polypharmacy.

Anticholinergic burden can increase healthcare resource utilization and costs.

Physicians should consider the total anticholinergic burden when managing older adults with OAB.

but can cause anticholinergic adverse effects, including dry mouth, blurred vision, constipation and somnolence [5]. These off-target effects are influenced by the drug's 
selectivity for different muscarinic receptor subtypes and its disposition (e.g., propensity to cross the blood-brain barrier) [6]. Many commonly prescribed medications (tricyclic antidepressants, certain antihistamines, etc.) also have off-target anticholinergic effects $[2,7]$.

Older individuals, who constitute a high proportion of the $\mathrm{OAB}$ population [8-10], may be more vulnerable to off-target anticholinergic effects [11]. Older patients have higher levels of comorbidity and polypharmacy, and are more likely to receive multiple drugs with anticholinergic activity [11]. Indeed, an estimated $20-50 \%$ of older people are routinely exposed to medicines with anticholinergic activity [12]. Furthermore, older individuals may have age-related decline in cholinergic function, increased blood-brain barrier permeability and altered drug pharmacokinetics, which may increase their sensitivity to anticholinergic effects [12]. Anticholinergic burden is the cumulative effect of multiple medications with varying degrees of anticholinergic activity [12] and can be measured using a range of scales, such as the Anticholinergic Drug Scale and Anticholinergic Activity Scale (general scales) and the Anticholinergic Cognitive Burden [ACB] scale and Anticholinergic Effect on Cognition [AEC] scale (cognitive scales) [13-15].

According to US, European and international urinary incontinence/OAB guidelines, the cumulative effects of anticholinergic drugs on cognition should be considered when prescribing treatment $[1-3,16]$. The American Geriatric Society also recommends keeping the number of anticholinergic drugs to a minimum in older people and avoiding some drugs with strong anticholinergic properties [7]. Cumulative anticholinergic burden has been shown to increase healthcare resource utilization (HRU) in a diverse ambulatory population aged $\geq 65$ years [17]. Furthermore, studies in patients with $\mathrm{OAB}$ have shown that $\mathrm{ACB}$ scores were higher than in those without $\mathrm{OAB}$ (and in about $60 \%$ of patients, $\geq 80 \%$ of the score was attributable exclusively to bladder anticholinergics) [18] and that higher anticholinergic burden was associated with higher rates of falls and fractures [19]. However, there is a lack of data on the effect of anticholinergic burden on HRU and related costs in patients with $\mathrm{OAB}$, despite the frequent use of bladder anticholinergic agents. The aim of the current study was therefore to evaluate the association between cumulative anticholinergic burden and HRU in older patients with OAB.

\section{Patients and Methods}

\subsection{Study Design and Population}

This was a retrospective, observational study using data from the UK Clinical Practice Research Datalink (CPRD)
GOLD database, a primary care database of anonymized medical records from general practitioners (GPs), who provide practice-level data on a monthly basis [20]. This includes information on demographics, diagnoses, signs and symptoms, prescriptions and referrals. Data were eligible for inclusion in the current study if a patient was aged $\geq 65$ years at the index date; had OAB (recorded $\mathrm{OAB}$ diagnosis Read code or OAB drug prescription between 1 April 2007 and 31 December 2015); had $\geq 3$ years of continuous enrolment before and $\geq 2$ years after the index date (i.e., the earliest possible date for the start of the pre-index period was 1 April 2004 and the latest possible date for the end of the post-index date 31 December 2017); and had CPRD data linked to Hospital Episodes Statistics (HES) data. The index date was the first date of OAB Read code recorded or first prescription for any $\mathrm{OAB}$ drug, i.e., patients were not treated with $\mathrm{OAB}$ drugs during the pre-index period. Start (1 April 2007) and end (31 December 2015) dates were chosen to allow a 3-year pre-index and a 2-year post-index period, taking into account HES data availability at the time analyses were conducted.

\subsection{Study Endpoints}

The primary endpoint was the association between cumulative anticholinergic burden (in the 3-year pre-index period) and HRU over the 2-year post-index period. The duration of the pre-index period (3 years) was based on the results of a longitudinal study that evaluated the cumulative use of strong anticholinergics and incident dementia. Risk was only increased with $>1096$ total standardized daily doses (TSDDs), which is equivalent to 3 years of daily dosing with a single strong anticholinergic [21]. In another publication, which evaluated longitudinal measures of anticholinergic burden, an exposure period of 1 year was chosen; however, the authors state that this was arbitrary and that the exposure period should be determined on a case-bycase basis [22]. It was therefore decided to use a 2-year post-index period in the current study, rather than just 1 year, to allow sufficient time to collect resource use data. Cumulative anticholinergic burden was measured using the widely used ACB scale, which assigns drugs with known anticholinergic activity a score of 1 (mild anticholinergics with possible anticholinergic effects), 2 (definite, moderate anticholinergic effects) or 3 (definite, strong anticholinergic effects) [17].

HRU was based on GP consultations (for any reason), specialist referrals (limited to geriatricians, psychiatrists and neurologists to capture the main complications associated with anticholinergic burden), urological tests (relevant Read codes from CPRD GOLD) and hospital admissions (inpatient and day care data from HES). Costs 
for each type of resource were estimated at the patient level by applying the unit cost associated with that type of resource; these were then used to calculate the total cost for each patient. Unit costs for HRU were derived from the National Health Service National Schedule of Reference Costs and relevant published data (electronic supplementary Table A1).

Additional endpoints were association between cumulative anticholinergic burden and HRU over the 3-year pre-index period; costs in the 3-year pre-index and 2-year post-index periods (according to ACB score in the 3-year pre-index period); ACB scores in the 2-year post-index period in the overall population and three subgroups: mirabegron-treated patients; patients treated with any bladder anticholinergic; and no $\mathrm{OAB}$ treatment (patients with a diagnosis of $\mathrm{OAB}$ but with no $\mathrm{OAB}$ drug prescription at the index date).

\subsection{Analyses}

The mean total daily ACB score was calculated according to the equation derived from Campbell et al. (see electronic supplementary appendix) [17]. Briefly, for each drug with anticholinergic effects, the ACB score was multiplied by the number of days of treatment, and the sum of these data was divided by the number of days with any anticholinergic medication prescribed. The resulting continuous scores were categorized as ACB scores of 0 (mean total daily scores 0 to $<0.5$ ), 1 (mean score 0.5 to $<1.5$ ), 2 (mean score 1.5 to $<2.5$ ), 3 (mean score 2.5 to $<3.5$ ) and $4+$ (mean score $\geq 3.5$ ). Patients' sociodemographic and clinical characteristics were compared among ACB score subgroups using the Chi-square test, $t$ test or analysis of variance.

The association between ACB (in the 3-year pre-index period) and HRU and associated costs in the 2-year postindex period were analyzed using multivariate regression methods (log-normal and generalized linear), with adjustment for potential confounding factors: patient age, sex, number of comedications (distinct British National Formulary $[\mathrm{BNF}]$ headers) and social deprivation class (Townsend score).

The following sensitivity analyses were conducted: analysis of data from patients with $\geq 5$ years of continuous enrollment pre-index (comparing ACB scores in the 3 years pre-index vs. scores in pre-index years $4-5$ ); assessment of anticholinergic burden using the AEC scale and the TSDD; and no minimum follow-up period. Sensitivity analyses using the AEC scale and TSDD were conducted to determine whether the results were affected by the scale used to assess cumulative anticholinergic burden.

\section{Results}

\subsection{Sociodemographic and Clinical Characteristics}

Overall, 194,083 people with an OAB diagnosis Read code or prescription for an $\mathrm{OAB}$ drug were identified using the CPRD GOLD database; after applying inclusion criteria (see the Methods section), data from 23,561 people were included in the main analysis (electronic supplementary Fig. A1). The majority (96.4\%) were included due to first prescription of an $\mathrm{OAB}$ drug (bladder anticholinergic, $n=22,537$; mirabegron, $n=168$ ). Most patients (61.5\%) were female and the mean age (standard deviation [SD]) was 76.0 years $(7.3)$ (Table 1$)$.

\subsection{Anticholinergic Cognitive Burden Scores}

In the 3-year pre-index period, mean (SD) daily ACB score was 1.0 (1.1) and the proportions of patients with ACB scores of $0,1,2,3$ and $4+$ were $43.5 \%, 36.8 \%, 9.8 \%, 6.4 \%$ and $3.5 \%$, respectively. There were statistically significant associations between ACB scores, and all sociodemographic and clinical characteristics examined (Table 1).

The mean (SD) daily ACB score in the 2-year post-index period was 2.4 (1.7) and the proportions of patients with ACB scores of $0,1,2,3$ and 4+ were 10.6\%, 24.3\%, 17.4\%, $29.5 \%$ and $18.1 \%$, respectively (Table 2 ). The greatest contributions to the ACB score in the post-index period came, as expected, from urological drugs (i.e., bladder anticholinergic agents, 58.8\%); antidepressants contributed $10.6 \%$ and analgesics contributed $6.3 \%$ (electronic supplementary Table A2).

\subsection{Association Between Anticholinergic Burden and Healthcare Resource Utilization (HRU) and Costs (Post-index Period)}

Post-index HRU (2-year total) according to the pre-index ACB score is shown in Table 3. All patients had $\geq 1$ GP consultation and many were hospitalized (55.6\%). Overall, $39.3 \%$ had $\geq 1$ urological test and $9.5 \%$ were referred to a specialist. The mean number of GP consultations increased from 26.4 (ACB score category 0 ) to 41.2 (category $4+$ ), and the proportion of patients with $\geq 1$ specialist referral increased from $8.5 \%$ (category 0 ) to $13.8 \%$ (category $4+$ ). Corresponding values for the proportion of patients with $\geq 1$ urological test were $37.2 \%$ and $45.9 \%$, respectively, and $51.3 \%$ and $67.1 \%$, respectively, for the proportion of patients with $\geq 1$ hospitalization.

Costs for GP consultations, specialist referrals and hospitalizations during the 2-year post-index period increased with increasing pre-index ACB score (Table 3). In those 
Table 1 Sociodemographic and clinical characteristics, overall and by ACB score subgroups

\begin{tabular}{|c|c|c|c|c|c|c|c|}
\hline \multirow[t]{2}{*}{ Characteristics } & \multirow[t]{2}{*}{$\begin{array}{l}\text { All } \\
{[n=23,561]}\end{array}$} & \multicolumn{5}{|c|}{$\begin{array}{l}\text { Mean total daily ACB scale score calculated within the 3-year pre-index } \\
\text { period }\end{array}$} & \multirow[t]{2}{*}{$p$ value $^{\mathrm{d}}$} \\
\hline & & $\begin{array}{l}0 \\
{[n=10,253]}\end{array}$ & $\begin{array}{l}1 \\
{[n=8667]}\end{array}$ & $\begin{array}{l}2 \\
{[n=2313]}\end{array}$ & $\begin{array}{l}3 \\
{[n=1500]}\end{array}$ & $\begin{array}{l}4+ \\
{[n=828]}\end{array}$ & \\
\hline Female $[n(\%)]$ & $14,481(61.5)$ & $6104(59.5)$ & $5322(61.4)$ & $1468(63.5)$ & $998(66.5)$ & $589(71.1)$ & $<0.0001$ \\
\hline Age at index date, years [mean (SD)] & $76.0(7.3)$ & $75.2(7.1)$ & $76.5(7.3)$ & $77.4(7.4)$ & $76.2(7.5)$ & $76.5(7.5)$ & $<0.0001$ \\
\hline \multicolumn{8}{|l|}{ IMD score at index date ${ }^{\mathrm{a}}[n(\%)]$} \\
\hline 1 & $3758(16.0)$ & $1723(16.8)$ & $1375(15.9)$ & $361(15.6)$ & $198(13.2)$ & $101(12.2)$ & \multirow[t]{5}{*}{$<0.0001$} \\
\hline 2 & $4752(20.2)$ & $2156(21.0)$ & $1694(19.5)$ & $451(19.5)$ & $290(19.3)$ & $161(19.4)$ & \\
\hline 3 & $4853(20.6)$ & $2101(20.5)$ & $1799(20.8)$ & $448(19.4)$ & $339(22.6)$ & $166(20.0)$ & \\
\hline 4 & $4784(20.3)$ & $2024(19.7)$ & $1793(20.7)$ & $477(20.6)$ & $312(20.8)$ & $178(21.5)$ & \\
\hline 5 & $5414(23.0)$ & $2249(21.9)$ & $2006(23.1)$ & $576(24.9)$ & $361(24.1)$ & $222(26.8)$ & \\
\hline \multicolumn{8}{|l|}{ Townsend score at index date ${ }^{\mathrm{b}}[n(\%)]$} \\
\hline 1 & $6254(26.6)$ & $2862(27.9)$ & $2279(26.3)$ & $561(24.3)$ & $363(24.2)$ & $189(22.8)$ & \multirow[t]{5}{*}{$<0.0001$} \\
\hline 2 & $5940(25.2)$ & $2632(25.7)$ & $2169(25.0)$ & $576(24.9)$ & $372(24.8)$ & $191(23.1)$ & \\
\hline 3 & $4907(20.8)$ & $2121(20.7)$ & $1762(20.3)$ & $507(21.9)$ & $348(23.2)$ & $169(20.4)$ & \\
\hline 4 & $4175(17.7)$ & $1754(17.1)$ & $1572(18.1)$ & $416(18.0)$ & $268(17.9)$ & $165(19.9)$ & \\
\hline 5 & 2275 (9.7) & 879 (8.6) & $881(10.2)$ & $252(10.9)$ & 149 (9.9) & $114(13.8)$ & \\
\hline $\begin{array}{l}\text { Polypharmacy }{ }^{\mathrm{c}} \text { within the } 1 \text {-month } \\
\text { pre-index period [mean }(\mathrm{SD})]\end{array}$ & $5.9(3.8)$ & $4.7(3.1)$ & $6.1(3.6)$ & $7.8(4.1)$ & $7.4(4.4)$ & $9.8(4.9)$ & $<0.0001$ \\
\hline
\end{tabular}

$A C B$ Anticholinergic Cognitive Burden, BNF British National Formulary, IMD Index of Multiple Deprivation (measured in 2015), $S D$ standard deviation

${ }^{a}$ Measured at the general practitioner practice location

${ }^{\mathrm{b}}$ Social deprivation class, measured at the patient location

${ }^{\mathrm{c}}$ Number of comedications (distinct BNF headers)

${ }^{\mathrm{d}}$ Data were analyzed using the Chi-square test, $t$ test or analysis of variance

Table 2 ACB scores according to type of treatment for OAB

\begin{tabular}{|c|c|c|c|c|}
\hline & \multirow{2}{*}{$\begin{array}{l}\text { Overall } \\
{[n=23,561]}\end{array}$} & \multicolumn{3}{|l|}{ Subgroup } \\
\hline & & $\begin{array}{l}\text { Mirabegron } \\
{[n=168]}\end{array}$ & $\begin{array}{l}\text { Any bladder anticholinergic } \\
{[n=22,537]}\end{array}$ & $\begin{array}{l}\text { No OAB treatment } \\
{[n=856]}\end{array}$ \\
\hline $\begin{array}{l}\text { Pre-index total daily ACB } \\
\text { score }[\text { mean }(\mathrm{SD})]\end{array}$ & $0.95(1.13)$ & $1.11(1.62)$ & $0.95(1.14)$ & $0.80(0.99)$ \\
\hline \multicolumn{5}{|c|}{ Pre-index total daily ACB score $[n(\%)]$} \\
\hline 0 & $10,253(43.5)$ & $63(37.5)$ & $9770(43.4)$ & $420(49.1)$ \\
\hline 1 & $8667(36.8)$ & $69(41.1)$ & $8286(36.8)$ & $312(36.4)$ \\
\hline 2 & $2313(9.8)$ & $16(9.5)$ & $2228(9.9)$ & $69(8.1)$ \\
\hline 3 & $1500(6.4)$ & $13(7.7)$ & $1452(6.4)$ & $35(4.1)$ \\
\hline $4+$ & $828(3.5 \%)$ & $7(4.2)$ & $801(3.6)$ & $20(2.3)$ \\
\hline $\begin{array}{l}\text { Post-index total daily ACB } \\
\text { score [mean (SD)] }\end{array}$ & $2.41(1.70)$ & $1.17(1.29)$ & $2.45(1.70)$ & $1.55(1.45)$ \\
\hline \multicolumn{5}{|c|}{ Post-index total daily ACB score $[n(\%)]$} \\
\hline 0 & $2502(10.6)$ & $68(40.5)$ & $2186(9.7)$ & $248(29.0)$ \\
\hline 1 & $5724(24.3)$ & $53(31.5)$ & $5409(24.0)$ & $262(30.6)$ \\
\hline 2 & $4109(17.4)$ & $18(10.7)$ & $3971(17.6)$ & $120(14.0)$ \\
\hline 3 & $6954(29.5)$ & $17(10.1)$ & $6785(30.1)$ & $152(17.8)$ \\
\hline $4+$ & $4272(18.1)$ & $12(7.1)$ & 4186 (18.6) & 74 (8.6) \\
\hline
\end{tabular}

$A C B$ anticholinergic cognitive burden, $O A B$ overactive bladder, $S D$ standard deviation 
Table $3 \mathrm{HRU}$ and costs during the 2-year post-index period according to the 3-year pre-index ACB score

\begin{tabular}{|c|c|c|c|c|c|c|}
\hline \multirow[t]{2}{*}{ Characteristics } & \multirow{2}{*}{$\begin{array}{l}\text { All } \\
{[n=23,561]}\end{array}$} & \multicolumn{5}{|c|}{ Mean total daily ACB score in the 3 -year pre-index period } \\
\hline & & $0[n=10,253]$ & $1[n=8667]$ & $2[n=2313]$ & $3[n=1500]$ & $4+[n=828]$ \\
\hline \multicolumn{7}{|c|}{ Primary care system resource use } \\
\hline $\begin{array}{l}\geq 1 \text { GP consultation } \\
{[n(\%)]}\end{array}$ & $23,561(100.0)$ & $10,253(100.0)$ & $8667(100.0)$ & $2313(100.0)$ & $1500(100.0)$ & $828(100.0)$ \\
\hline $\begin{array}{c}\text { Number of GP } \\
\text { consultations } \\
\text { [mean (SD)] }\end{array}$ & $30.5(22.0)$ & $26.4(18.8)$ & $31.2(21.4)$ & $37.9(26.3)$ & $36.9(26.8)$ & $41.2(29.7)$ \\
\hline $\begin{array}{l}\text { Total cost }(£) \text { of } \\
\text { GP consultations } \\
{[\text { mean }(\mathrm{SD})]}\end{array}$ & $1232.40(969.10)$ & $1056.10(820.30)$ & $1261.80(932.10)$ & $1559.90(1192.80)$ & $1500.40(1169.40)$ & $1706.80(1342.90)$ \\
\hline \multicolumn{7}{|c|}{ Secondary care system resource use } \\
\hline $\begin{array}{l}\geq 1 \text { specialist referral } \\
{[n(\%)]}\end{array}$ & $2243(9.5)$ & $872(8.5)$ & $800(9.2)$ & $280(12.1)$ & $177(11.8)$ & $114(13.8)$ \\
\hline $\begin{array}{l}\text { Number of spe- } \\
\text { cialist referrals } \\
\text { [mean (SD)] }\end{array}$ & $0.1(0.4)$ & $0.1(0.4)$ & $0.1(0.4)$ & $0.2(0.5)$ & $0.2(0.5)$ & $0.2(0.6)$ \\
\hline 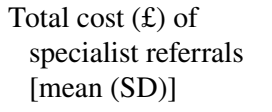 & $25.00(89.00)$ & $22.10(81.80)$ & $23.90(86.10)$ & $32.60(98.90)$ & $32.40(110.50)$ & $38.80(123.10)$ \\
\hline $\begin{array}{l}\geq 1 \text { urological test } \\
{[n(\%)]}\end{array}$ & 9254 (39.3) & $3809(37.2)$ & $3426(39.5)$ & $1017(44.0)$ & $622(41.5)$ & $380(45.9)$ \\
\hline $\begin{array}{l}\text { Number of urological } \\
\text { tests [mean (SD)] }\end{array}$ & $0.8(1.7)$ & $0.8(1.5)$ & $0.9(1.7)$ & $1.0(1.8)$ & $1.0(1.8)$ & $1.0(1.9)$ \\
\hline $\begin{array}{l}\text { Total cost }(\mathfrak{f}) \text { of } \\
\text { urological tests } \\
{[\text { mean }(\mathrm{SD})]}\end{array}$ & $37.90(115.60)$ & $37.70(119.60)$ & $38.50(116.30)$ & $36.90(104.90)$ & $38.20(111.00)$ & $38.00(93.30)$ \\
\hline \multicolumn{7}{|l|}{$\begin{array}{l}\text { Hospitalizations } \\
{[n(\%)]}\end{array}$} \\
\hline No hospitalizations & $10,467(44.4)$ & 4995 (48.7) & $3759(43.4)$ & $845(36.5)$ & $596(39.7)$ & $272(32.9)$ \\
\hline Day care & $8602(36.5)$ & $3550(34.6)$ & $3191(36.8)$ & $956(41.3)$ & $569(37.9)$ & $336(40.6)$ \\
\hline In-patient & $8546(36.3)$ & 3237 (31.6) & $3211(37.0)$ & $1043(45.1)$ & $642(42.8)$ & $413(49.9)$ \\
\hline $\begin{array}{l}\text { Number of day care } \\
\text { hospitalizations } \\
\text { [mean (SD)] }\end{array}$ & $0.8(3.8)$ & $0.8(4.1)$ & $0.9(4.1)$ & $0.8(1.9)$ & $1.0(2.9)$ & $0.9(1.8)$ \\
\hline $\begin{array}{l}\text { Number of in-patient } \\
\text { stays [mean (SD)] }\end{array}$ & $0.7(1.4)$ & $0.6(1.2)$ & $0.7(1.4)$ & $1.0(1.6)$ & $1.0(1.9)$ & $1.3(2.0)$ \\
\hline $\begin{array}{l}\text { Total cost }(\mathfrak{f}) \text { of } \\
\text { hospitalizations } \\
{[\text { mean }(\mathrm{SD})]^{\mathrm{a}}}\end{array}$ & $2388.70(4573.80)$ & $1961.10(3967.10)$ & $2440.50(4296.30)$ & $3096.70(5124.20)$ & $3307.70(7218.30)$ & $3654.80(5749.10)$ \\
\hline
\end{tabular}

$A C B$ anticholinergic cognitive burden, $G P$ general practitioner, $H R U$ healthcare resource utilization, $S D$ standard deviation

${ }^{\text {a }}$ From 2010 only ( $n=15,002$ patients), as hospitalization costs were not available before this time

with ACB category scores of $0-4$, mean costs for GP consultations ranged from $£ 1056.10$ to $£ 1706.80$, respectively; $£ 22.10$ to $£ 38.80$, respectively, for specialist referrals; and $£ 1961.10$ to $£ 3654.80$, respectively, for hospitalizations.

After adjusting for patient baseline characteristics and unweighted ACB scores at the index date, the number of GP consultations was statistically significantly greater for patients with pre-index ACB scores $\geq 1$ versus those with a score of 0 ( $p<0.0001$ for all comparisons; log-normal regression model). Those with ACB scores of 1, 2, 3 and 4+ were expected to have $10.2 \%, 20.3 \%, 19.6 \%$ and $18.7 \%$ more GP consultations, respectively, than those with a score of 0 . There was also a trend for an increase in the odds ratio (OR) for specialist referrals as pre-index ACB score increased (Fig. 1). Compared with those with a pre-index ACB score of 0 , the odds of having a urological test or being hospitalized were higher in those with pre-index ACB scores $\geq 1$ (Fig. 1).

After adjusting for patient baseline characteristics and unweighted ACB scores at the index date, total costs were 
statistically significantly higher for patients with pre-index ACB scores of 1,2, 3 and 4+ versus those with a score of 0 ( $p<0.0001$ for all comparisons; generalized linear model). Similar results were obtained when hospitalization costs were excluded.

\subsection{Association between Pre-index Anticholinergic Burden and Pre-Index HRU and Costs}

Almost all patients (99.5\%) had $\geq 1 \mathrm{GP}$ consultation during the 3-year pre-index period, and most $(56.8 \%)$ attended hospital. Almost half of all patients had urological tests (46.4\%) and $10 \%$ were referred to a specialist.

HRU and corresponding costs generally increased with increasing ACB score (Table 4). The mean numbers of GP consultations were 21.5 for ACB category 0 , and 53.4 for category $4+$, with corresponding costs of $£ 1264.50$ and $£ 2192.70$, respectively. The proportions of patients with $\geq 1$ specialist referral were $8.0 \%$ (category 0 ) and $16.2 \%$ (category 4+), with costs of $£ 20.30$ and $£ 44.10$, respectively. Corresponding values for the proportions of patients who did not require hospitalization were $61.0 \%$ and $47.6 \%$, respectively; costs associated with hospitalization were $£ 1861.00$ and $£ 3896.50$, respectively.

\subsection{Anticholinergic Burden in Subgroups in the Post-index Period}

Mean (SD) post-index ACB scores were 1.2 (1.3) in the mirabegron group, 2.5 (1.7) in the bladder anticholinergic subgroup, and 1.5 (1.5) in the no $\mathrm{OAB}$ treatment group

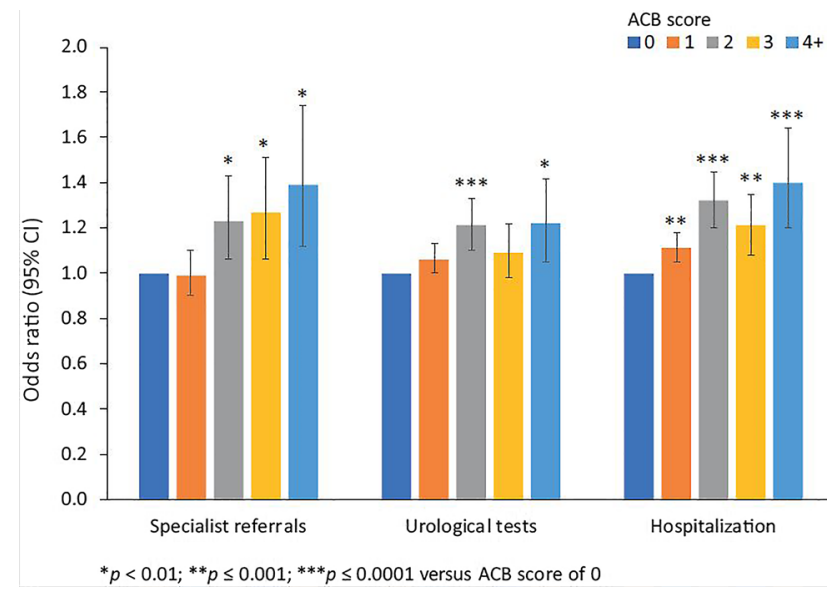

Fig. 1 Post-index HRU according to the pre-index mean total ACB score (logistic regression model). Results were adjusted for patient baseline characteristics (age, sex, Townsend score [social deprivation class] and number of co-medications [number of distinct BNF headers]) and unweighted $\mathrm{ACB}$ score at index date. $A C B$ anticholinergic cognitive burden, $B N F$ British National Formulary, $C I$ confidence interval, $H R U$ healthcare resource utilization
(Table 2). Mean (SD) daily pre-index ACB scores were similar in the three subgroups (1.1 [1.6], 1.0 [1.1] and 0.8 [1.0], respectively). Overall, $17.2 \%$ of patients in the mirabegron group had a post-index ACB score of $\geq 3$, compared with $48.7 \%$ in the bladder anticholinergic group. Urologicals (i.e., bladder anticholinergics) contributed to $20.5 \%$ and $59.4 \%$ of the ACB scores, respectively. Other drugs contributing $>10 \%$ (in either group) were antidepressants $(27.5 \%$ and $10.4 \%$, respectively), analgesics $(11.1 \%$ and $6.2 \%$, respectively) and diuretics (10.1\% and 3.8\%, respectively) [electronic supplementary Table A2].

\subsection{Sensitivity Analyses}

Results of the sensitivity analyses are presented in the electronic supplementary Appendix. The association between ACB scores and HRU was similar to that for the main analysis.

\section{Discussion}

This is the first study to evaluate the association between cumulative anticholinergic burden, HRU and costs in older patients with $\mathrm{OAB}$. The results suggest that an increase in anticholinergic burden was generally associated with increased HRU and increased costs after adjusting for significant confounders.

In the current study population, the mean (SD) ACB score was 1.0 (1.1) and approximately $10 \%$ of patients had a mean total ACB score of $\geq 3$ during the 3-year pre-index period. Despite this, $95.7 \%$ were starting first-line bladder anticholinergic treatment for $\mathrm{OAB}$ at the index date. This is perhaps not surprising as the only pharmacological nonanticholinergic treatment for OAB (mirabegron) was not launched until 2013. Initiation of bladder anticholinergic treatment at the index date could add significantly to their underlying anticholinergic burden. Indeed, post-index mean total daily ACB scores were approximately 1.5 points higher versus pre-index scores (and $48.7 \%$ had a mean score $\geq 3$ ) in patients starting a bladder anticholinergic agent. In comparison, post-index scores in patients starting mirabegron were only approximately 0.1 points higher than pre-index scores (and $17.2 \%$ had a mean score $\geq 3$ ). Interpretation of these results is limited by the relatively small number of mirabegron-treated patients; however, as mirabegron is not an anticholinergic, it provides one way to avoid adding to anticholinergic burden in the older OAB population. Studies evaluating mirabegron in $\mathrm{OAB}$ in older patients have shown that it is effective and has a favourable tolerability profile compared with bladder anticholinergic agents, especially with respect to rates of dry mouth [23-29]. Before prescribing a treatment for $\mathrm{OAB}$, it is also important that clinicians 
Table 4 HRU and costs during the 3-year pre-index period according to the pre-index ACB score

\begin{tabular}{|c|c|c|c|c|c|c|}
\hline \multirow[t]{2}{*}{ Characteristics } & \multirow{2}{*}{$\begin{array}{l}\text { All } \\
{[n=23,561]}\end{array}$} & \multicolumn{5}{|c|}{ Mean total daily ACB score in the 3 -year pre-index period } \\
\hline & & $0[n=10,253]$ & $1[n=8667]$ & $2[n=2313]$ & $3[n=1500]$ & $4+[n=828]$ \\
\hline \multicolumn{7}{|c|}{ Primary care system resource use } \\
\hline $\begin{array}{l}\geq 1 \text { GP consultation } \\
{[n(\%)]}\end{array}$ & $23,446(99.5)$ & $10,199(99.5)$ & $8629(99.6)$ & $2299(99.4)$ & $1497(99.8)$ & $822(99.3)$ \\
\hline $\begin{array}{c}\text { Number of GP } \\
\text { consultations } \\
\text { [mean (SD)] }\end{array}$ & $38.0(26.9)$ & $31.6(21.5)$ & $39.8(26.1)$ & $49.2(32.5)$ & $46.0(31.2)$ & $53.4(41.4)$ \\
\hline $\begin{array}{l}\text { Total cost }(£) \text { of } \\
\text { GP consultations } \\
{[\text { mean }(\mathrm{SD})]}\end{array}$ & $1532.90(1148.00)$ & $1264.50(895.70)$ & $1603.00(1107.20)$ & $2005.60(1427.80)$ & $1870.20(1344.70)$ & $2192.70(1888.40)$ \\
\hline \multicolumn{7}{|c|}{ Secondary care system resource use } \\
\hline $\begin{array}{l}\geq 1 \text { specialist referral } \\
{[n(\%)]}\end{array}$ & $2346(10.0)$ & $820(8.0)$ & $863(10.0)$ & $318(13.7)$ & $211(14.1)$ & $134(16.2)$ \\
\hline $\begin{array}{l}\text { Number of spe- } \\
\text { cialist referrals } \\
\text { [mean (SD)] }\end{array}$ & $0.1(0.5)$ & $0.1(0.4)$ & $0.1(0.5)$ & $0.2(0.6)$ & $0.2(0.5)$ & $0.2(0.6)$ \\
\hline 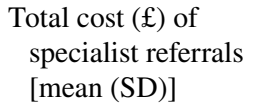 & $26.00(89.50)$ & $20.30(78.30)$ & $26.00(89.30)$ & $38.40(112.40)$ & $35.60(101.60)$ & $44.10(115.30)$ \\
\hline $\begin{array}{l}\geq 1 \text { urological test } \\
{[n(\%)]}\end{array}$ & $10,934(46.4)$ & $4441(43.3)$ & $4154(47.9)$ & $1183(51.1)$ & $731(48.7)$ & $425(51.3)$ \\
\hline $\begin{array}{l}\text { Number of urological } \\
\text { tests [mean (SD)] }\end{array}$ & $1.1(1.9)$ & $0.9(1.7)$ & $1.1(2.0)$ & $1.3(2.4)$ & $1.2(2.1)$ & $1.3(2.1)$ \\
\hline $\begin{array}{c}\text { Total cost }(£) \text { per } \\
\text { urological test } \\
{[\text { mean }(\mathrm{SD})]}\end{array}$ & $43.00(131.10)$ & $40.20(128.70)$ & $45.00(137.10)$ & $47.80(128.80)$ & $42.00(124.30)$ & $45.10(111.70)$ \\
\hline \multicolumn{7}{|l|}{$\begin{array}{l}\text { Hospitalizations } \\
{[n(\%)]}\end{array}$} \\
\hline No hospitalizations & $13,389(56.8)$ & $6255(61.0)$ & $4810(55.5)$ & $1165(50.4)$ & $765(51.0)$ & $394(47.6)$ \\
\hline Day care & $6901(29.3)$ & $2801(27.3)$ & $2607(30.1)$ & 754 (32.6) & $477(31.8)$ & $262(31.6)$ \\
\hline In-patient & $6616(28.1)$ & $2383(23.2)$ & $2586(29.8)$ & $836(36.1)$ & $491(32.7)$ & $320(38.6)$ \\
\hline $\begin{array}{l}\text { Number of day care } \\
\text { hospitalizations } \\
\text { [mean (SD)] }\end{array}$ & $0.7(4.2)$ & $0.6(5.9)$ & $0.7(1.9)$ & $0.7(2.1)$ & $0.8(3.3)$ & $0.7(1.6)$ \\
\hline $\begin{array}{l}\text { Number of in-patient } \\
\text { stays [mean (SD)] }\end{array}$ & $0.6(1.3)$ & $0.4(1.0)$ & $0.6(1.3)$ & $0.8(1.6)$ & $0.7(2.1)$ & $1.0(2.1)$ \\
\hline $\begin{array}{l}\text { Total cost }(\mathfrak{f}) \text { of } \\
\text { hospitalizations } \\
{[\text { mean }(\mathrm{SD})]^{\mathrm{a}}}\end{array}$ & $2456.70(4791.60)$ & $1861.00(3822.00)$ & $2633.80(4713.00)$ & $3522.60(5520.40)$ & $3240.80(7751.40)$ & $3896.50(6101.90)$ \\
\hline
\end{tabular}

$A C B$ anticholinergic cognitive burden, $G P$ general practitioner, $H R U$ healthcare resource utilization, $S D$ standard deviation

${ }^{\text {a }}$ From 2010 only ( $n=15,002$ patients), as hospitalization costs were not available before this time

assess patients' existing medications with a view to reducing the anticholinergic burden if possible.

The results obtained are generally consistent with a previous study from a general population, which showed that a 1-point increase in cumulative anticholinergic burden (also assessed using the ACB score) was associated with a significant increase in HRU [17]. The current study extends these findings by looking specifically at older patients with $\mathrm{OAB}$ and showing that costs generally rise with increasing cumulative anticholinergic burden.
The study does have some limitations inherent to its design. Use of the UK CPRD database means that the extent to which the results can be extrapolated to countries outside the UK is unclear, as there may be differences in licensed/ commonly used drugs with anticholinergic properties, prescribing practices and guidelines, and funding arrangements. One of the other limitations of using the CPRD database is that it provides drug prescription data only. Information on whether drugs are taken as prescribed is not available, and it does not include information on over-the-counter 
(OTC) medication use. A future study in which adherence with anticholinergic medication and OTC medication use are taken into account may add value, but at the expense of patient numbers. It would also be interesting to assess the extent to which anticholinergic burden is related to the target and off-target effects of drugs, and explore the qualitative impact of cumulative anticholinergic burden on quality of life.

Another limitation of the current study is the potential for survivor bias, as it was based on patients with data available for at least 2 years after $O A B$ diagnosis/first OAB prescription. However, this was addressed by one of the sensitivity analyses, which included data regardless of the duration of follow-up, and generated similar results to the main analysis. There may have also been additional factors (e.g., body mass index, smoking status, etc.) contributing to resource use that were not adjusted for in the analyses. Comorbid conditions were not adjusted for per se, as the definitions used in this study did not reflect comorbidities coding in UK general practice, but the number of co-medications was used as a proxy. Finally, the current analysis did not investigate the contribution of post-index anticholinergic burden on HRU, although adjustment was made for the unweighted ACB score on the index date. The results obtained for the association between anticholinergic burden and HRU and costs in the pre-index period should be interpreted with caution as it is not known whether ACB exposure occurred before or after the HRU events.

Despite the limitations highlighted above, use of the UK CPRD database does have benefits. It includes data from 35 million people in the UK and provides a longitudinal dataset that is representative of the UK population. It is widely used internationally for epidemiological research across a broad range of health outcomes, producing over 1000 studies published in peer-reviewed journals [20]. The results therefore provide a useful indicator of the association between cumulative anticholinergic burden and HRU and costs in patients with $\mathrm{OAB}$. The results also provide longitudinal data for clinicians, which is more useful than cross-sectional information, particularly in relation to cumulative anticholinergic burden.

In the current study, the primary analysis was based on calculations using the ACB scale. This is the most widely used scale in studies quantifying anticholinergic burden and has been found to be well-suited to analyzing administrative data [30], although there is no gold standard. We therefore performed a sensitivity analysis using the AEC scale [31] and this provided similar results to the ACB. The AEC scale is relevant to the current study population, as the scale was based on a list of drugs commonly used in older patients in the UK. It also downgrades the scores of many drugs (including some bladder anticholinergic agents) if they do not penetrate the CNS or there is no clinical evidence for cognitive effects. Indeed, only $5.0 \%$ of patients had a preindex score of 3 or more using the AEC compared with $9.9 \%$ using the $\mathrm{ACB}$, and a score of 1 or more was seen in $26.3 \%$ and $56.5 \%$ of patients, respectively. It should be noted that both the ACB and AEC focus on cognition and may not accurately quantify anticholinergic burden in the periphery, where effects on dry mouth, constipation, etc. also contribute to HRU.

\section{Conclusions}

The results of the current study show that, at the point of $\mathrm{OAB}$ diagnosis or initiation of first-line treatment, patients aged $\geq 65$ years already have some underlying anticholinergic burden. Higher anticholinergic burden before initiating OAB drugs is associated with higher HRU and costs. As such, clinicians and decision makers should evaluate overall anticholinergic burden for patients $>65$ years with $\mathrm{OAB}$, including the use of alternative treatment options to bladder anticholinergic agents, to help reduce anticholinergic burden and associated resource use.

Supplementary Information The online version contains supplementary material available at https://doi.org/10.1007/s40266-021-00884-0.

Acknowledgements The authors would like to thank Robert Snijder for his assistance with data analysis and Ian Eustace for medical writing support during development of the study report. Medical writing support for manuscript development was provided by Nicky French, PhD, of Bioscript Group, Macclesfield, UK, funded by Astellas.

\section{Declarations}

Funding This study was supported by Manchester Metropolitan University and funded by Astellas Pharma Europe Ltd (APEL). APEL was involved in the design and conduct of the study; data acquisition; data analysis; data interpretation; manuscript preparation; manuscript review; and manuscript approval.

Conflict of interest ES, PC, ML and NC are employees of Astellas Pharma Europe Ltd (APEL). JN was an employee of APEL at the time of study conduct but is now employed by Swedish Orphan Biovitrum (Sobi) Ltd. AJ and MA completed secondments at APEL under a Knowledge Transfer Partnership scheme with Manchester Metropoli$\tan$ University when the research was conducted. FF was a member of the Knowledge Transfer Partnership team, which received research grants from APEL. CQ is an employee of Creativ-Ceutical, which was contracted by APEL to perform the study reported. XT was an employee of Creativ-Ceutical at the time of study conduct.

Author contributions All authors contributed to the development of the manuscript, approved the final version before submission, and agree to be accountable for all aspects of the work. AJ, JN, FF, MA, ES, PC, ML, and NC contributed to the conception and design of the study; AJ, $\mathrm{CQ}, \mathrm{XT}$, and ML acquired the data; AJ, JN, FF, CQ, ES, PC, XT, ML, and $\mathrm{NC}$ conducted the data analysis and interpretation; CQ and XT 
conducted the statistical analyses; JN, FF, and ML obtained funding; $\mathrm{AJ}, \mathrm{FF}, \mathrm{MA}$, and ML provided administrative, technical or material support; AJ, JN, and ML provided supervision; ML contributed to the study report preparation, review and finalization process. This study is based in part on data from the CPRD obtained under license from the UK Medicines and Healthcare products Regulatory Agency. The data are provided by patients and are collected by the NHS as part of their care and support. The interpretation and conclusions contained in this study are those of the author/s alone.

Data availability statement Data are not available to other researchers. Access to anonymized individual participant-level data will not be provided for this study as it meets one or more of the exceptions described on www.clinicalstudydatarequest.com under 'Sponsor Specific Details for Astellas'.

Open Access This article is licensed under a Creative Commons Attribution-NonCommercial 4.0 International License, which permits any non-commercial use, sharing, adaptation, distribution and reproduction in any medium or format, as long as you give appropriate credit to the original author(s) and the source, provide a link to the Creative Commons licence, and indicate if changes were made. The images or other third party material in this article are included in the article's Creative Commons licence, unless indicated otherwise in a credit line to the material. If material is not included in the article's Creative Commons licence and your intended use is not permitted by statutory regulation or exceeds the permitted use, you will need to obtain permission directly from the copyright holder. To view a copy of this licence, visit http://creativecommons.org/licenses/by-nc/4.0/.

\section{References}

1. Burkhard FC, Bosch JLHR, Cruz F, Lemack GR, Nambiar AK, Thiruchelvam N, et al. EAU Guidelines: Urinary Incontinence 2019. https://uroweb.org/guideline/urinary-incontinence/\#4. Accessed May 2019

2. International Continence Society. Incontinence (6th edition) 2017. https://www.ics.org/publications/ici_6/Incontinence_6th_Edition 2017_eBook_v2.pdf. Accessed Aug 2019.

3. National Institute for Health and Care Excellence. Urinary incontinence and pelvic organ prolapse in women: management. https:// www.nice.org.uk/guidance/ng123. Accessed May 2019.

4. Deeks ED. Mirabegron: a review in overactive bladder syndrome. Drugs. 2018;78(8):833-44.

5. Collamati A, Martone AM, Poscia A, Brandi V, Celi M, Marxetti $\mathrm{E}$, et al. Anticholinergic drugs and negative outcomes in the older population: from biological plausibility to clinical evidence. Aging Clin Exp Res. 2016;28(1):25-35.

6. Abrams P, Andersson KE, Buccafusco JJ, Chapple C, de Groat WC, Fryer AD, et al. Muscarinic receptors: their distribution and function in body systems, and the implications for treating overactive bladder. Br J Pharmacol. 2006;148(5):565-78.

7. American Geriatrics Society Beers Criteria ${ }^{\circledR}$ Update Expert Panel. American Geriatrics Society updated AGS Beers Criteria for potentially inappropriate medication use in older adults. J Am Geriatr Soc. 2019;67(4):674-94.

8. Milsom I, Abrams P, Cardozo L, Roberts RG, Thuroff J, Wein AJ. How widespread are the symptoms of an overactive bladder and how are they managed? A population-based prevalence study. BJU Int. 2001;87(9):760-6.
9. Stewart WF, Van Rooyen JB, Cundiff GW, Abrams P, Herzog AR, Corey $\mathrm{R}$, et al. Prevalence and burden of overactive bladder in the United States. World J Urol. 2003;20(6):327-36.

10. Irwin DE, Milsom I, Hunskaar S, Reilly K, Kopp Z, Herschorn S, et al. Population-based survey of urinary incontinence, overactive bladder, and other lower urinary tract symptoms in five countries: results of the EPIC study. Eur Urol. 2006;50(6):1306-14.

11. Pierce H, Thomas D, Asfaw T, Chughtai B. Anticholinergic burden in the elderly population: an emerging concern. Eur Urol. 2019;76(1):7-8.

12. Nishtala PS, Salahudeen MS, Hilmer SN. Anticholinergics: theoretical and clinical overview. Expert Opin Drug Saf. 2016;15(6):753-68.

13. Boustani M, Campbell N, Munger S, Maidment I, Fox C. Impact of anticholinergics on the aging brain: a review and practical application. Aging Health. 2008;4(3):311-20.

14. Salahudeen MS, Nishtala PS. Examination and estimation of anticholinergic burden: current trends and implications for future research. Drugs Aging. 2016;33(5):305-13.

15. Salahudeen MS, Duffull SB, Nishtala PS. Anticholinergic burden quantified by anticholinergic risk scales and adverse outcomes in older people: a systematic review. BMC Geriatr. 2015;15:31.

16. Lightner DJ, Gomelsky A, Souter L, Vasavada SP. Diagnosis and treatment of overactive bladder (non-neurogenic) in adults: AUA/ SUFU guideline amendment 2019. J Urol. 2019;202(3):558-63.

17. Campbell NL, Perkins AJ, Bradt P, Perk S, Wielage RC, Boustani MA, et al. Association of anticholinergic burden with cognitive impairment and health care utilization among a diverse ambulatory older adult population. Pharmacotherapy. 2016;36(11):1123-31.

18. Yoshida M, Kato D, Nishimura T, Van Schyndle J, Uno S, Kimura T. Anticholinergic burden in the Japanese elderly population: use of antimuscarinic medications for overactive bladder patients. Int J Urol. 2018;25(10):855-62.

19. Szabo SM, Gooch K, Schermer C, Walker D, Lozano-Ortega G, Rogula B, et al. Association between cumulative anticholinergic burden and falls and fractures in patients with overactive bladder: US-based retrospective cohort study. BMJ Open. 2019;9(5):e026391.

20. Herrett E, Gallagher AM, Bhaskaran K, Forbes H, Mathur R, van Staa T, et al. Data resource profile: clinical practice research datalink (CPRD). Int J Epidemiol. 2015;44(3):827-36.

21. Gray SL, Anderson ML, Dublin S, Hanlon JT, Hubbard R, Walker R, et al. Cumulative use of strong anticholinergics and incident dementia: a prospective cohort study. JAMA Intern Med. 2015;175(3):401-7.

22. Lozano-Ortega G, Szabo SM, Cheung A, Suehs B, Caplan EO, Wagg A, et al. An evaluation of longitudinal measures of anticholinergic exposure for application in retrospective administrative data analyses. Adv Ther. 2019;36(9):2247-59.

23. Wagg A, Cardozo L, Nitti VW, Castro-Diaz D, Auerbach S, Blauwet MB, et al. The efficacy and tolerability of the $\beta 3$-adrenoceptor agonist mirabegron for the treatment of symptoms of overactive bladder in older patients. Age Ageing. 2014;43(5):666-75.

24. Mueller ER, van Maanen R, Chapple C, Abrams P, Herschorn $\mathrm{S}$, Robinson D, et al. Long-term treatment of older patients with overactive bladder using a combination of mirabegron and solifenacin: a prespecified analysis from the randomized, phase III SYNERGY II study. Neurourol Urodyn. 2019;38(2):779-92.

25. Foley S, Choudhury N, Huang M, Stari A, Nazir J, Freeman R. Quality of life in patients aged 65 years and older with overactive bladder treated with mirabegron across eight European countries: secondary analysis of BELIEVE. Int J Urol. 2019;26(9):890-6.

26. Kelleher C, Hakimi Z, Zur R, Siddiqui E, Maman K, Aballea $\mathrm{S}$, et al. Efficacy and tolerability of mirabegron compared with 
antimuscarinic monotherapy or combination therapies for overactive bladder: a systematic review and network meta-analysis. Eur Urol. 2018;74(3):324-33.

27. Chapple CR, Cruz F, Cardozo L, Staskin D, Herschorn S, Choudhury N, et al. Safety and efficacy of mirabegron: analysis of a large integrated clinical trial database of patients with overactive bladder receiving mirabegron, antimuscarinics, or placebo. Eur Urol. 2020;77(1):119-28.

28. Wagg A, Staskin D, Engel E, Herschorn S, Kristy RM, Schermer CR. Efficacy, safety, and tolerability of mirabegron in patients aged $\geq 65$ year with overactive bladder wet: a phase IV, doubleblind, randomized, placebo-controlled study (PILLAR). Eur Urol. 2020;77(2):211-20
29. Staskin D, Herschorn S, Fialkov J, Tu LM, Walsh T, Schermer CR. A prospective, double-blind, randomized, two-period crossover, multicenter study to evaluate tolerability and patient preference between mirabegron and tolterodine in patients with overactive bladder (PREFER study). Int Urogynecol J. 2018;29(2):273-83.

30. Lozano-Ortega G, Johnston KM, Cheung A, Wagg A, Campbell NL, Dmochowski RR, et al. A review of published anticholinergic scales and measures and their applicability in database analyses. Arch Gerontol Geriatr. 2020;87:103855.

31. Bishara D, Harwood D, Sauer J, Taylor DM. Anticholinergic effect on cognition (AEC) of drugs commonly used in older people. Int J Geriatr Psychiatry. 2017;32(6):650-6. 